\title{
Situation Analysis of Health Care System of Pakistan: Post 18 Amendments
}

\author{
Saad Ahmed Khan* \\ Dadabhoy Institute of Higher Education, Pakistan
}

\begin{abstract}
Objective of the study: The aim of this paper is to highlight the actions taken by the government in various health performance system domains post $18^{\text {th }}$ Amendment.

Methodology: Health system performance domains were identified through the websites of WHO and Eastern Mediterranean Regional Office of WHO (EMRO). Then the actions required in various health system performance domains were identified and the literature related to health system performance domains and $18^{\text {th }}$ Amendment was reviewed through electronic databases and health care acts and related bills of each province. Inter-provincial analysis was done analyzing the vision, mission, aims and objectives of each and every provincial healthcare commission along with the monitoring and evaluation, licensing, governance and complaint systems provided on the respective databases of each province.

Results: This will surely help in attaining the access, quality and equity to health care services.

Conclusion: The health system is in process of regeneration, with provincial empowerment in the country's federal system. While $18^{\text {th }}$ Constitutional Amendment has created opportunities as well challenges, but the possible way forward to improve health sector is improving the governance system.
\end{abstract}

Keywords: Health; $18^{\text {th }}$ Amendment; Health system performance domains; Health governance; Health policy

\section{INTRODUCTION}

In Pakistan decentralization took the form of devolution of powers. This was introduced by General Musharraf back in 2000, as a devolution plan and was adopted by the Provincial governments as 'Local Government Ordinance' in 2001. This plan was based on five principles that is (1) Devolution of political power (2) Deconcentration of management functions (3) Decentralization of administrative authority (4) Distribution of resources to the district level and (5) Diffusion of the power-authority link [1].

Still, the health care system of Pakistan is in a complicated phase. Because decentralization strategy was actually used to strengthen centralization in Pakistan [2]. However, to address this issue parliament unanimously passed $18^{\text {th }}$ Amendment on $20^{\text {th }}$ April, 2010, thereby, dividing power and sovereignty between national and regional levels of governments in order to reduce the likelihood of an authoritarian or overly centralized government. Taking this into account provinces took active steps to pass provincial health bills. Thus, respective bills were passed by Punjab health commission (PHC) in 2010, Sindh health commission (SHCC) in 2014 and Khyber Pakhtunkhwa in 2015 [3-5].
The bills were passed to ensure promulgation of following roles in the healthcare department of different provinces. Thereby, Punjab healthcare commission bill was passed with an aim to improve the quality of healthcare service delivery by implementing 'Minimum Service Delivery Standards (MSDS)' and to ban quackery in all its forms [3]. Whereas, Sindh Healthcare Commission bill was passed with an aim to make provision for improved access, equity and quality of healthcare services, to ban quackery and to provide for ancillary matters [4]. However, Khyber Pakhtunkhwa healthcare commission bill was passed with an aim to provide people with safe and high quality health care services [5]. But still, there is neither any commission for province of Baluchistan nor any bill is passed for the health care delivery services for the people of Baluchistan at the provincial level.

In each of the bills that were promulgated at provincial levels, the needs of the healthcare system were highlighted in various domains which include: (1) Governance (2) Registration and Licensing (3) Standards of healthcare services (4) Inspection and enforcement (5) Funds, budget and accounts.

Correspondence to: Saad Ahmed Khan, Dadabhoy Institute of Higher Education, Pakistan, E-mail: saad.khan@dadabhoy.edu.pk

Received: April 24, 2019; Accepted: May 23, 2019; Published: May 31, 2019

Citation: Khan SA (2019) Situation Analysis of Health Care System of Pakistan: Post 18 Amendments. Health Care Current Reviews 7: 244. doi: $10.35248 / 2375-4273.19 .7 .244$.

Copyright: (C) 2019 Khan SA. This is an open-access article distributed under the terms of the Creative Commons Attribution License, which permits unrestricted use, distribution, and reproduction in any medium, provided the original author and source are credited. 
But, health indicators still lags behind in achieving set targets thereby provides a depressing account.

(1) In health financing domain, Government is expending only $0.4 \%$ (50 billion PKR) of GDP on health. Whereas, almost $78 \%$ of the general population pays out of their pockets for medical treatment.

(2) Health Workforce indicates insufficient human resource. There is approximately 1:1300 Doctor- patient ratio and 1:2.7 Doctornurse ratios which is very low as recommended by WHO [6].

(3) Organization and Service Delivery in Pakistan indicates that there is an absence of programs for non-communicable diseases at provincial and federal levels. The regulatory arrangements for medicines are unsatisfactory. There is a lack of proper health diagnostic facilities and medical education. In particular, there is absence of health information-related institutions.

The health care system of Pakistan is also facing an increased challenge to achieve Millennium Development Goals (MDGs). MDG-3 states 'Health for All' but "Presently, Maternal and Infant Mortality Rates are as high as 260 per 100,000 deaths and 61.27 per 1,000 live births, respectively. In addition, almost $19 \%$ of the general population and $30 \%$ of children under five years of age are mal-nourished [7].”

In addition to these, macroeconomic issues of government further complicate the problem. The government of Pakistan has limited its ability to increase health finance and expenditure. Moreover, a large burden of population demanding scarce resources redirection. And finally, the administrative and political changes in the health system of Pakistan.

The creation of a national public health network of institutions and professionals is necessary for effective planning in health reforms [8]. A number of elements are responsible for this scenario, however feeble health system leadership \& governance and planning \& implementation challenges are dominant factors [9].

The aim of this paper is to highlight the actions taken by the government in various health performance system domains post $18^{\text {th }}$ Amendment.

\section{HEALTH SITUATION POST 18 AMENDMENT}

The $18^{\text {th }}$ Amendment is the "holding together" vision of federalism, also known as the "new federalism." It is an attempt to decentralize roles and responsibilities in the mixed health system of Pakistan. Thereby, to foresee secessionist propensities and to overcome the regional discontent with central policies. Hence, according to the Devolution Initiative (DI), the roles and responsibilities in the mixed health system were mapped to manage different levels of service providers and to avoid replication. In the words of a Chinese philosopher, "All long journeys start with the first small steps." The $18^{\text {th }}$ Amendment must be seen as that first step in the long journey to restore Pakistan to its original glory [10].

The $18^{\text {th }}$ Amendment can be considered as a first step toward the fundamental restructuring of the mixed health governance system in Pakistan. This is because the amendment have offered some prospective for public governance improvement. But on the other hand, also introduces major risks for economic and political union. In Pakistan, there have been many attempts at decentralization [11]. The $18^{\text {th }}$ Constitutional Amendment has devolved many systems' mandate as a welcome step towards improved governance and leadership. Thereby, it approved long-promised autonomy to provinces and granted them health responsibilities as their mandate. Thus, Provincial government's needs (1) to improve plans and policies for health finance and expenditure increment (2) for restructuring of public facilities (3) to establish engagement between public and private (4) develop compliant policy for human resources under $18^{\text {th }}$ Constitutional Amendment and (5) ensure provincial drug regulation capacity [12]. However, the constitution still dictates the roles and responsibilities of federal government about the national roles in health. These include, (1) overarching policy norms (2) health information (3) federal fiscalism (4) trade in health (5) external resource mobilization and (6) interprovincial regulation and coordination [13].

But, a long-awaited change in the health sector of Pakistan in the form of $18^{\text {th }}$ Amendment has brought more confusion than clarity. The reason of this confusion is that the health sector has become a provincial matter, thereby, dissolving the Ministry of Health, resultantly. Probably, now Pakistan is the only country in the world without the Health Minister at the national level. Therefore, the health sector of Pakistan is likely to suffer more in future, until and unless abstruseness is removed. And there would be a clear demarcation of roles and responsibilities at federal and provincial level.

Therefore, in reality, the sharing out of responsibilities altered over time between the provinces and the districts. Thereby, the health sector has suffered badly, due to lack of experience as well as capacity that delayed the progress and influenced the general population negatively. Consequently, issues started to arose after devolution which included (1) absence of initiative for overseeing federal health responsibilities (2) lack of funds at provincial level for proper functioning of health programs (3) lack of drug regulation (4) lack of proper mechanism for transferring of power to provinces (5) lack of mechanism to involve community in decision-making (6) misuse of funds at provincial level due to lack of capacity etc. [14].

In addition, many other factors are involved that influence the success or failure of decentralization. These factors include (1) lack of adequate preparation (2) lack of strategy for implementation (3) inadequate financing (4) the mind-set of federal bureaucracy and weak capacity at all levels. Moreover, health care service could not be delivered satisfactorily by any of the province due to lack of interest, experience and financial capacity. The division of financing between provinces and districts have made it difficult for the districts to work properly. As in all provinces, developmental budget is retained at upper level. While the bulk of recurrent costs for service delivery, were managed at the district levels [15-17].

Furthermore, in the context of Pakistan, many questions have been posed by the devolution of health sector. These questions are posed in terms of (1) The provinces' capacity for policies regulation and health planning (2) Leadership and strategic directions (3) Generation of health information (4) Development of human resource and international agreements $[13,18]$.

As a consequence, post $18^{\text {th }}$ Amendment, the Pakistan's mixed health system syndrome has been accompanied by a deterioration of both law and order. Thereby, declining of quality and quantity of public services. The dysfunction of public governance in Pakistan has reached a tipping point which has provoked the media to label it as a "failing" state. Whereas, some Pakistani scholars have already labeled it a "failed state" [19]. Low literacy rate along with low health care budgetary expenditure, extreme poverty, lack of 
skilled professional in the health field, population explosion, and insufficient health care facilities, have further weakened the state.

\section{METHODOLOGY}

\section{Identification of health system performance domains}

The websites of WHO and Eastern Mediterranean Regional Office of WHO (EMRO) were searched to identify health system performance domains. Thereby, data was extracted and analyzed after taking guidance through WHO's Building Blocks Framework that is a conceptual framework model for assessment of health system performance domains. The criteria that support the health system performance domains were also drawn from the WHO analysis on the features of government role in health system in the well-developed and developed countries. The WHO framework basically emphasize on six relational domains of health system performance including: (1) Health system leadership and governance (2) Health Financing (3) Health Care services (4) Health Workforce (5) Health Information and (6) Medical products, Vaccines and Technologies [20].

\section{Actions required in the health system domains}

After the identification of health system performance domain through the WHO framework, we started to assess the health system performance in different domains in Pakistan after the $18^{\text {th }}$
Constitutional Amendment. We followed many papers including that of Nishtar (2013) to identify the required actions needed to be performed in various domains of the health system to create the fiscal space for health system and to widen the base public means financing. This will surely help in attaining the access, quality and equity to health care services. Mentioned below are the actions required as per the Nishtar (2013) in different domains of health system of Pakistan for its better performance or else system failure could be noticed (Table 1) [12].

Reviewing of Current online databases: The literature related to health system performance domains and $18^{\text {th }}$ Amendment was reviewed through three electronic databases (Google Scholar, Pubmed and MEDLINE) containing publications in English without restrictions on the publication date.

On the other hand, online databases for healthcare commission of each province of Pakistan were also searched and different systems were analyzed for each domain of health system performance. In addition, to this health care acts and related bills of each province were also analyzed. Vision, mission aims and objectives of each and every provincial healthcare commission were analyzed along with the monitoring and evaluation, licensing, clinical governance and compliant systems provided on the respective databases of each province.

Tabulation: Tabulation was based on the extraction of actions required in every health system performance domain from

Table 1: Actions required in different Health system domains of Pakistan.

\begin{tabular}{|c|c|c|}
\hline S. No. & Health System Performance Domains & Various Actions Required \\
\hline 1. & Health care Leadership and Governance & $\begin{array}{l}\text { - Health governing structures should promote meritorious, transparent and accountable reforms. } \\
\text { - A health structure which stabilize national functions. } \\
\text { - Appropriate health policy, laws and organizational frameworks are required at both federal and } \\
\text { - Revincial levels. } \\
\text { - Regulation of private sector require policies and services package. } \\
\text { clear vision of health responsibilities. }\end{array}$ \\
\hline 2. & Health care service delivery & $\begin{array}{l}\text { - State owned public facilities should be restructured with regular counter check. } \\
\text { - Primary health care should be focused expendably } \\
\text { - National public health programs should be incorporated at the district and provincial levels. } \\
\text { - Health gaps of the general population should be bridge in service delivery. } \\
\text { - Hospitals should be reformed by improving equity and quality. } \\
\text { - Proper system of public funded services provided by private donors. }\end{array}$ \\
\hline 3. & Health system finance and expenditure & $\begin{array}{l}\text { - Economic and commercial space for health can be created by mobilizing liberal and pioneer } \\
\text { budget, commercial responsibility and arrears constraint. } \\
\text { - Public financing can be extended by socializing finance methods. } \\
\text { - Increase in interest allocation for health along with increased gross domestic product (GDP). } \\
\text { - Increased exposure of insurance or insurance schemes is a pooling criterion required as a } \\
\text { platform for formally employed individuals. } \\
\text { - Restoring existing system of government's social protection and scaling up of new ideas with } \\
\text { better transparency and targeting of informal sector. }\end{array}$ \\
\hline 4. & Health System Human Resource & - Health workforce complaint policy is required after implementation of 18th Amendment. \\
\hline 5. & Health system Products and Technologies & $\begin{array}{l}\text { - Drug regulatory authority needs to be transparent, meritorious, and strictly strong at federal } \\
\text { level. } \\
\text { - National laws and Drug policy need to be revised. } \\
\text { - Support dimensions should be setup. }\end{array}$ \\
\hline 6. & $\begin{array}{l}\text { Health system Information, } \\
\text { Communication \& Technology }\end{array}$ & $\begin{array}{l}\text { - E-health laws and legislation should be authentic, supportable, demand-driven and standards. } \\
\text { - Projects having potential to progress can be up-scaled and institutionalize by providing incentives. } \\
\text { - Establishment of Disease response and surveillance system. } \\
\text { - Health information system should be institutionalized for private and public sectors at district } \\
\text { level. } \\
\text { - Policy analysis should support self-governing think tanks. } \\
\text { - Representative population registries development should be supported. }\end{array}$ \\
\hline
\end{tabular}


the paper of Nishtar et al., as mentioned above. Whereas interprovincial analysis is based on the assessment of online healthcare commission databases of each province along with the respective health acts of each province, different government documents and review articles and papers related to $18^{\text {th }}$ Amendment and Health system performance of Pakistan in various domains.

\section{HEALTH SYSTEM LEADERSHIP \& GOVERNANCE SITUATION}

Leadership and Governance is considered as a key determining factor of inclusive development, social advancement and economic progression. It also contributes in the execution of the MDGs in low and middle income countries like Pakistan [21]. Good governance and Leadership is characterized by liability, transparency and significant participation of community. This plays an important role in the public health sector for the sustainability of donorfunded health systems projects [22].

In the health sector, leadership and governance have been largely treated as a set of roles and responsibilities that are assumed to be carried out under the course of health ministries. Leadership and governance is progressively recognized as a critical factor in the performance of health system. Whereas, it still remains below par theoretically as well as practically. And a poorly understood subject of both what its role and responsibilities are and how its weaknesses could be addressed [23].

Generally, accepted health system goals include: (1) Preventive and promotional programmes and equitable access health services for health status improvement, (2) Genuine responsiveness to public and patient expectations and (3) Fair financing thereby protecting the needy against financial risks [24,25]. In this regard, leadership and governance responsibilities require active management of state actors as well as some other actors to achieve these goals. State actors have been specified in Health system governance through various analyses $[25,26]$. Thereby, three categories are recognized through which health leadership and governance is become operationalized. The relationship of these principal-agents reflects principles of good leadership and governance. It is also related to how governance helps to achieve health system goals [27].

1) The first category of state actors include: Government officials, policy makers and politicians. In addition to these Health ministry, insurance agencies and public entities for procurement and distribution of pharmaceuticals works in central. However, regulatory bodies, finance ministry, judicial system and parliamentary committees for health have roles as well [28].

2) The second category of actors constitutes health service providers which include providers from all public, private and voluntary sectors. These include hospitals, laboratories, clinics and educational institutes. It also consist of health maintenance organizations, pharmaceutical industry, insurance agencies and equipment manufacturers and suppliers $[29,30]$.

3) The third category of actors includes general public, service users and organized civil society (professional associations and advocacy organizations) [31]. This category of actors is sub categorized in number of ways. These ways include: by income (poor vs. non-poor), by service (maternal and child health, reproductive health, geriatric care) by location (rural vs. urban) and/or by disease or condition (HIV/AIDS, TB, malaria, etc.).
When symptoms of compromised equity and quality are shown through a mixed public and private health-care delivery system, it can be considered as "mixed health systems syndrome". Characters of this syndrome could be identified through key indicators of poor performance of health systems. These include failure to achieve fair financing and out of pocket payments by general population [32]. It can also be identified, when health care delivery is predominantly becomes the mandate of private sector and performance and management problems start to manifest in the public system. These problems are reflective as poor responsiveness. In addition, incompetency to achieve equity in outcomes is endemic to mixed health system syndrome.

The above mentioned factors hypothesize that health systems' poor performance is dependent on the relationship between various factors. These include (i) insufficient budget for health; (ii) delivery of social services by private sector in a regulatory environment without a suitable regulatory framework; and (iii) lack of accountability and transparency in leadership \& governance. The triad of these factors act together to compromise public services quality and equity to health system care access in multiple ways [33].

Mixed Health System Syndrome in Pakistan is characterized by (1) lack of regulation of private sector, (2) poor public financing, and (3) overall limitations in leadership and governance. These have led to the issues of health care access, equity and quality [12]. It could now be rightly said that, "Systemic constraints have affected the health system and its performance". And thereby systemic reforms in health governance domain could be introduced to resolve this key issue.

Reform could be introduced to impact deeply the health system performance by promoting accountability and transparency in governance \& leadership. This could be done through financial and public services management. In addition, primary health care services could be broaden through regulatory approaches. This can enable the use of private sector to achieve overall greater equity [12]. Health governance reforms are related to broader systemic reforms like open media can increase societal political responsiveness in this regard. Thereby, "health for all" objectives of mixed health system with appropriate stewardship, can only be pursued by, (1) expanding finance and expenditure in health system and (2) connecting to private providers [33].

Ultimately, the inter-provincial difference in health Governance domain post $18^{\text {th }}$ Amendment is seen as Table 2:

\section{HEALTH CARE SERVICE DELIVERY SITUATION}

An epidemiological transition is faced by Pakistan these days in form of double burden of communicable diseases along with maternal and perinatal as well as infectious diseases. Thus in order to achieve millennium development goals and substantial improvement in healthcare service delivery, a well-rounded health policy should be formulated. The quality of public health services has been decreasing over the last few decades with increasing burden of population. The diminished role of public health facilities has contributed to poor state of public facilities. To bridge this gap private sector has enormously increased the provision of health care service delivery [34]. But this has put Pakistan among one of the countries with highest shares of out-of-pocket expenditure relative to total health expenditure in healthcare service delivery [35]. 
Table 2: Inter-provincial difference in health Governance domain post $18^{\text {th }}$ Amendment.

\begin{tabular}{|c|c|c|c|c|c|}
\hline S.No & Actions Required & Punjab & Sindh & Khyber Pakhtunkhwa & Baluchistan \\
\hline 1 & $\begin{array}{c}\text { Accountability, transparency and merit promoting } \\
\text { reforms }\end{array}$ & Absent & Absent & Absent & Absent \\
\hline 2 & $\begin{array}{c}\text { Health structure consistent with spirit of } \\
\text { devolution }\end{array}$ & Absent & Absent & Absent & Absent \\
\hline 3 & $\begin{array}{l}\text { Appropriate and relevant policies and institutional } \\
\text { frameworks at national and federal levels }\end{array}$ & Present & Present & Present & Absent \\
\hline 4 & $\begin{array}{c}\text { Service packages and policies for regulation of } \\
\text { private sectors }\end{array}$ & Absent & Present & Present & Absent \\
\hline 5 & Clarity of health roles after decentralization & Absent & Absent & Absent & Absent \\
\hline
\end{tabular}

When assessing the situation of health care service delivery in Pakistan, the picture is critical and not much promising. The situation is more worrying when service provision and utilization is analyzed among rural areas of different provinces which are at vibrant disadvantage in terms of service delivery at primary and tertiary healthcare service levels. However, difference is also found among different provinces like service delivery in Punjab and Khyber Pakhtunkhwa has increased over time but the gap is still prevailing in healthcare service delivery in both Sindh and Baluchistan at rural and urban settings [36]. In addition, difference in healthcare delivery services is also seen among various districts within a province. This all situation basically not only reflects the healthcare service delivery but also impose why private healthcare setting is in more demand among the people inspite of its high cost and out-of-pocket expenditures [36]. Ultimately, the interprovincial difference in healthcare service delivery post $18^{\text {th }}$ Amendment is seen as Table 3:

\section{HEALTH SYSTEM FINANCE AND EXPENDITURE SITUATION}

Public health expenditure in Pakistan is very less than that in other countries of the world [37]. That is Pakistan is expending only $0.4 \%$ of its GDP (50 billion PKR) on health. However, funding dominated by out of pocket payments contributes to $78.08 \%$. In addition, to this it is also dominated by external resources to NGOs, private insurances, government revenues, world funding and developmental partners [38]. Though, major source of government health financing is general taxation [39]. Whereas, $60 \%$ of health expenditure is now accounted for in district budgets [40]. Thus, proper strategies and strong federal-provincial relations are required for the strengthening of public sector funds thereby, to alleviate the health disparities of the country. It has been recommended by WHO to allocate $6 \%$ of the GDP for health to cater the deteriorating health conditions of the country [34].

After the $18^{\text {th }}$ Constitutional Amendment, health has now become the provincial mandate. And unfortunately, no health policy exists in the country to guide the provinces in this regard. Instead they are expected to develop their own health policies at provincial level. However, Pakistan still needs a comprehensible agenda for health at national level. As without the federal regulation, provinces will be unable to share national health information, donor co-ordination and financial forecasting [41]. The increased responsibilities on provinces require upgradation of management and institutional capacities, which are not present at the moment. In addition to the formulation of health policies and agendas, provinces also require a profound monitoring system for the execution of these policies to scale-up performance in health care delivery services [34]. Ultimately, the inter-provincial difference in health finance and expenditure domain post $18^{\text {th }}$ Amendment is seen as Table 4:

\section{HEALTH SYSTEM HUMAN RESOURCE SITUATION}

Pakistan rank sixth in the world population wise and as per its requirement the health human workforce in quite insufficient. Pakistan is one of the 57 countries that critically deficient in human health resource [42]. In Pakistan doctor to patient ration is $1: 1300$, nurse to patient ratio is $1: 20$ whereas, doctor to nurse ratio is $1: 2.7$. However, according to $\mathrm{WHO}$, it is recommended that doctor to patient ratio should be 1:1000, whereas, appropriate doctor to nurse ratio is $1: 4$ [43]. In addition, according to the Pakistan Nursing Council the nurse to patient ratio should be 1:10 and 2:1 in genera and specialized areas, respectively [44].

Human health workforce play a very important role in the provision of quality health care delivery services to the people. But at present, Pakistan is having shortage of qualified midwives, pharmacists, public health experts, dentists and physiotherapists etc. [12]. However, approximately 90,000 lady health workers are working in the rural areas for the healthcare delivery; still the need of the country is not met yet. Thereby, Pakistan still lack behind in achieving its health goals for following reasons: (1) medicine stock outs, (2) out of time salaries, (3) inappropriate program planning, (4) unavailability or non-functioning of medical equipments [6]. Ultimately, the inter-provincial difference in human health workforce domain post $18^{\text {th }}$ Amendment is seen as Table 5.

\section{HEALTH SYSTEM MEDICAL PRODUCTS \& TECHNOLOGIES SITUATION}

According to WHO, Pakistan is having 60,000 registered medical products from 495 local and 30 multinational companies, but none of them is approved by any regulatory body [45]. However, with the evolving medicine, technology and community needs, Pakistan's national drug policy (1996) and drug act (1976) should be revised [12]. In principle, health facilities provide free medicines, when available, whereas, most of the public health facilities suffer from frequent stock out of medicines which ultimately force patients and general public to produce drug of their own through out-of-pocket expenditure. On the other hand, procurement and standard operating procedures of medicines, equipments and various technologies does not met technically set national guidelines. Similarly, there is no existing policy for the upgradation and replacement of equipments after they have completed their devaluation period, making the equipment compromised and nonfunctional [46]. 
Table 3: Inter-provincial difference in healthcare service delivery domain post $18^{\text {th }}$ Amendment.

\begin{tabular}{|c|c|c|c|c|c|}
\hline S.No & Actions Required & Punjab & Sindh & Khyber Pakhtunkhwa & Baluchistan \\
\hline $\mathbf{1}$ & Restructuring of public facilities & Present & Absent & Present & Absent \\
\hline $\mathbf{2}$ & Expanded focus on primary healthcare & Present & Present & Present & Absent \\
\hline $\mathbf{3}$ & Integration of devolved national public health programmes & Present & Absent & Present & Absent \\
\hline $\mathbf{4}$ & Bridging of the population health gap & Present & Absent & Present & Absent \\
\hline $\mathbf{5}$ & Reformed hospitals through decentralization & Absent & Absent & Absent & Absent \\
\hline 6 & $\begin{array}{c}\text { Role of private providers in delivering publicly funded } \\
\text { services }\end{array}$ & Present & Present & Present & Absent \\
\hline
\end{tabular}

Table 4: Inter-provincial difference in health finance and expenditure domain post $18^{\text {th }}$ Amendment.

\begin{tabular}{|c|c|c|c|c|c|}
\hline S.No & Action Required & Punjab & Sindh & Khyber Pakhtunkhwa & Baluchistan \\
\hline $\mathbf{1}$ & $\begin{array}{c}\text { Progressive and innovative revenue mobilization along with } \\
\text { fiscal limitation and debt limitation to create fiscal space }\end{array}$ & Absent & Absent & Absent \\
\hline $\mathbf{2}$ & Mix of financing approaches to broaden public financing & Present & Present & Present \\
\hline $\mathbf{3}$ & Increase in health revenue allocations & Absent & Absent & Absent \\
\hline $\mathbf{4}$ & Increased insurance coverage & Present & Present & Present & Absent \\
\hline $\mathbf{5}$ & Revamp's of government existing system & Absent & Absent & Absent & Absent \\
\hline
\end{tabular}

Table 5: Inter-provincial difference in human health workforce domain post $18^{\text {th }}$ Amendment.

\begin{tabular}{|c|c|c|c|c|c|}
\hline S.No & Action Required & Punjab & Sindh & Khyber Pakhtunkhwa & Baluchistan \\
\hline 1 & $\begin{array}{l}\text { Complaint policy for human resource for } \\
\text { health }\end{array}$ & Present & Present & Present & Absent \\
\hline
\end{tabular}

According to telecommunication authority the use of internet and mobile phones in Pakistan has reached above 132 million, but public health sector has not devised any opportunity as an effective approach to spread health related information to the general public for the sake of prevention and treatment of diseases $[47,12]$. Ultimately, the inter-provincial difference in human health workforce domain post $18^{\text {th }}$ Amendment is seen as Table 6 .

\section{HEALTH SYSTEM INFORMATION, COMMUNICATION \& TECHNOLOGY SITUATION}

The infrastructure of Pakistan's health system is extensive and is spanning throughout the country but it lacks resources which include instrument supplies and technologies [48]. However, poor record maintenance, limited use of information technology and unsuitable infrastructure is seen in Pakistan [49]. In addition, in public health sector there is absence of health management information system (HMIS) along with the not well defined health policies for under developed infrastructure and technology and telemedicine implementation [44].

Furthermore, health institutions still lack certain tools and technologies to prepared skilled and competent health professionals. Moreover, the process of licensing and certification is very poor along with the inappropriate performance evaluation of health professionals across the country. Vital registration and notifiable disease reporting through the legislative framework for health information is also absent at the national level. But certain private health sectors and armed forces hospitals in the country are well equipped with latest technologies, have HMIS and properly managed and developed infrastructure. Whereas, rural areas of Gilgit Baltistan have also implemented e-health in the area [44]. Ultimately, the inter-provincial difference in health system information, communication and technology domain post $18^{\text {th }}$ Amendment are seen as Table 7 .

\section{CHALLENGES FOR HEALTH MINISTRY ON PROVINCIAL LEVEL POST $18^{\mathrm{TH}}$ AMENDMENT}

Reforming role and responsibilities: The roles and responsibilities of all tiers of Pakistani government including, federal, provincial, local, and beyond government should be comprehensively reviewed in delivering public health services. Instead, the amendment simply focuses on devolution of functions from the federal to the provincial level and neglect the streamlining of functions at both levels. Moreover, it also completely neglects the role and responsibilities in public services delivery of local and beyond-localgovernment entities [10].

Organizational restructure: Federal government has failed to realign its organizational structure according to the new mandate for the implementation of the amendment. Thereby, it continues to finance vertical health programs with its line agencies and retained all jobless employees instead of establishing specific grant programs and their accountability mechanisms. It has also directed the National Centre for Human Development, Planning Commission and Higher Education Commission to continue their roles and responsibilities without rethinking and institutionalizing new structures for the performance of these roles post amendment [10].

Financial restructuring: The financing at the provincial level through fiscal transfer has not been re-examined post amendment. Whereas, the financing provided by the federal government to the provinces for expenditure in social services and infrastructure responsibilities to set minimal national standards is very low. However, at present, no specific instrument is available to advance national objectives and to promote the spending power of federal government [10].

Regulatory standards: The devolution of powers has created major irregularities in concerned areas like pharmaceutical regulations; requirement of national uniform standards for drug approval; 
Table 6: Inter-provincial difference in human health workforce domain post $18^{\text {th }}$ Amendment.

\begin{tabular}{|c|c|c|c|c|c|}
\hline S.No & Actions required & Punjab & Sindh & Khyber Pakhtunkhwa & Baluchistan \\
\hline 1 & $\begin{array}{c}\text { Transparently governed and technically robust federal } \\
\text { drug regulatory authority }\end{array}$ & Absent & Absent & Absent & Absent \\
\hline $\mathbf{2}$ & Revision of national drug policy and law & Absent & Absent & Absent & Absent \\
\hline 3 & Stepping up support capacity & Absent & Absent & Absent & Absent \\
\hline
\end{tabular}

Table 7: Inter-provincial difference in health system information, communication and technology domain post $18^{\text {th }}$ Amendment.

\begin{tabular}{|c|c|c|c|c|c|}
\hline S.No & Actions required & Punjab & Sindh & Khyber Pakhtunkhwa & Baluchistan \\
\hline $\mathbf{1}$ & $\begin{array}{c}\text { Evidence based standards-compliant-e-health } \\
\text { legislation }\end{array}$ & Present & Present & Present & Absent \\
\hline $\mathbf{2}$ & $\begin{array}{c}\text { Incentives for upscaling and institutionalization of } \\
\text { existing pilots and projects }\end{array}$ & Present & Absent & Present \\
\hline $\mathbf{3}$ & Integrated disease surveillance and response & Absent & Absent & Absent & Absent \\
\hline $\mathbf{4}$ & District health information system for public sectors & Present & Absent & Present & Absent \\
\hline $\mathbf{5}$ & Appropriate policy interventions & Absent & Absent & Absent \\
\hline $\mathbf{6}$ & Support to develop registries of representative & Absent & Absent & Absent \\
\hline
\end{tabular}

inspection for food and agricultural safety; hazardous material control and disposal; pollution of waste, water and air; standards for highway safety; standards for consumer product safety and social safety nets. These all areas have now been demoted to the provinces which created a potential environment of confusion and contradiction regarding standards with high amenability and administration costs. The consequences for businesses and consumers could not be imagined, if each province is authorized to set up its own regulatory standards for different agencies, as postulated in the amendment [10].

Decision making authority and lack of accountability: In most large countries, provinces empowerment does not necessarily suggest that decision-making authority has moved closer to the people. Whereas, far removing decision-making infers that provincial governments have incomplete agreements with their citizens which cannot be held to account by citizens. In Pakistan, as politics is dominated by military, feudal, and industrial creams, this lack of accountability can estrange the governments from their people completely [10].

Administrative challenges: Significant inefficiencies could be created in public health service provision by concentrating the administrative power at the provincial level that may be aggravated by the extensiveness of provincial control. These measures may also limit the participation of private and non-profit organizations in improving public health services access [50].

\section{POSSIBLE SOLUTIONS AND ITS BENEFIT}

The challenges mentioned above can be averted by reforms which include fiscal responsibility framework which binds all tiers of government, disseminating all barriers to good mobility, thereby, creating a common union. The unfinished reform agenda should include local government's reasserting home rule and considering them as the responsible primary agents for delivering public health services, enriching the local economy, improving social and economic outcomes for its residents, guaranteeing its citizens' liberty and right to life and property. It would also include citizens' rights to information and to embrace governments accountable for their performance.

\section{REFORMS IN HEALTH SECTOR INCLUDE}

\section{Federal health authority}

National health functions need to be fulfilled as an imperative to maintain a federal structure for health. Reconfiguration of Federal health organizations is required and development of appropriate reporting relationships with the Health Division is necessary to better serve the national health functions [51]."

Political ownership: Health has never been deliberated as the political priority in Pakistan as evident from the low fiscal support to health sector by the President. The public health issues and their possible solutions have never been debated. However, various efforts and projects have been reformed due to change in policy vacillation and government. Therefore, political support to the health sector is required [8].

Allocation of health budget: The public health sector spending needs to be increase at least to $5 \%$ of GDP at both federal and provincial level. In the existing environment, health sector can be improved, if the resources are managed sensibly with all financial constraints. The eradication of corruption can also bring about an improvement in health sector as health is one of the most corrupt sectors in Pakistan [8].

Access to health care: Health care services can be employed with targeted access to address financial barriers. Particularly the poorest class should be targeted with special nutrition and maternal, newborn, and child health $(\mathrm{MNCH})$ programs, in addition to social protection innovation [8].

Public-private partnership: The cooperation between public and private health sectors can also improve health care facilities access. The provincial could also engage with private sector to enhance their capacities and outreach, before undertaking any project. As in Pakistan, consultation of private health providers is quite high; therefore, policies for private sector regulation and essential service packages are also required [52].

Federal and provincial coordination: At present, there is no authority working for monitoring and evaluation of health sector at the federal level, after the abolition of Pakistan's Ministry of 
Health post 18 amendment. Thereby, there is a dire need of a particular federal institutional system that could support provincial departments of health. Along with it, laws related to health need to be revised for providing better health opportunities. "At federal level, the focus should be on technical support, coordination, and discharging of responsibility instead of financial controls over provinces and exercising bureaucratic, which was the case before the $18^{\text {th }}$ Amendment [53]”.

National health policy: The unified national vision of Pakistan, as per promoting role of federal-provincial equity, there is a dire need of a national health policy. Health should be considered as a 'nation building agenda' by all provinces [8].

Separation of responsibilities: Pre 18 amendment, the responsibilities of Health Ministry and that of Population overlapped, which created administrative problems in implementation of various health programs. Therefore, policy making should be separated from analysis, oversight and regulation and replication should be avoided [8,54-58].

\section{CONCLUSION}

While $18^{\text {th }}$ Constitutional Amendment has created opportunities as well challenges, but the possible way forward to improve health sector is improving the governance system. This would need significant changes at the provincial level for effective management which include (1) management of stewardship functions through administrative reorganization (2) strengthening of management structures that are responsible for implementing management functions of national programme (3) increasing finance and expenditure for the national programmes and health systems for disease control and surveillance.

The health system is in process of regeneration, with provincial empowerment in the country's federal system. All of the above mentioned reforms have significant implications for MDGs, if the system is devolved as predicted. And provincial systems are not strengthened or reorganized; it is likely that Pakistan may slip further in the achievement of MDGs.

\section{REFERENCES}

1. http://www.nrb.gov.pk/publications/LG_Final_Plan_2000.pdf

2. Cheema A, Khwaja AI, Khan A. Decentralization in Pakistan: Context, content and causes. 2005.

3. https://www.phc.org.pk/act.aspx

4. http://shcc.org.pk/page/about-us/background

5. http://www.hcc.gkp.pk/about.php

6. Qarani WM, Kanji SI. Health system analysis: Pakistan and Afghanistan. Int J Endorsing Health Sci Res. 2015;3.

7. https://www.cia.gov/redirects/ciaredirect.html

8. Sana MA. An Appraisal of Health Sector in the Backdrop of 18th Amendment. ISSRA PAPERS. p: 45.

9. Jalal S. Revisiting the three different tiers of the health system of Pakistan and their implications for the achievement of MDGs by Pakistan. J Pakistan Med Ass. 2014;64(2):p:195.

10. Shah A. The 18th Constitutional Amendment: Glue or solvent for nation building and citizenship in Pakistan. Lahore J Economic. 2012;17:p:387.
11. Collins CD, Omar M, Tarin E. Decentralization, health care and policy process in the Punjab, Pakistan in the 1990s. Int J Health Planning Manage. 2002;17(2):123-146.

12. Nishtar S. Pakistan's health system: Performance and prospects after the 18th Constitutional Amendment. Lancet. 2013;381(9884):2193-2206.

13. http://www.heartfile.org/pdf/HEALTH_18AM_FINAL.pdf

14. Khan AA, Ahmed Z, Siddiqui MA, Sami N. Devolution of health sector in Pakistan after 18th constitutional amendment: Issues and possible solutions. J College Phys Surg Pakistan. 2014;24(4):295-295.

15. Plan LG. National Reconstruction Bureau 2000. Ministry of Health, Islamabad. Government of Pakistan. 2001.

16. Micronutrient Initiative and Nutrient Wing, Islamabad. Government of Pakistan 2005.

17. Lee R, Mason A. Population aging, wealth, and economic growth: Demographic dividends and public policy. 2007.

18. Strategic appraisal of 18th amendment: Federal/Provincial roles and impact on service delivery. Senior Management Wing, National Management College, Islamabad.

19. Haque N. Pakistan: A failed state. Int Food Policy Res Inst. 2009.

20. Everybody's business Strengthening health systems to improve health outcomes: WHOs framework for action. 2007.

21. Siddiqi S, Masud T, Nishtar S, Peters DH, Sabri B, Bile KM, et al. Framework for assessing governance of the health system in developing countries: Gateway to good governance. Health policy. 2009;90(1):13-25.

22. Israr SM, Islam A. Good governance and sustainability: A case study from Pakistan. Int J Health Planning Manage. 2006;21(4):313-325.

23. Brinkerhoff DW, Bossert TJ. Health governance: principal: Agent linkages and health system strengthening. Health Policy Planning. 2013;29(6):685-693.

24. Roberts M, William H, Peter B, Michael RR. Getting health reform right: A guide to improving performance and equity. Oxford university press. 2003.

25. The world health report: Health systems. Improv PerforM. WHO. 2000.

26. Frenk J. Dimensions of health system reform. Health Policy. $1994 ; 27(1): 19-34$

27. United Nations Development Program. Governance for Sustainable Human Development. 1997.

28. Brinkerhoff DW. Accountability and health systems: Toward conceptual clarity and policy relevance. Health Policy Planning. 2004;19(6):371-379.

29. Bennett S. Working with the non-state sector to achieve public health goals. 2005.

30. Nachuk S, Kundra SS. Public Stewardship of Private Providers in Mixed Health Systems.

31. Tantivess S, Walt G. The role of state and non-state actors in the policy process: The contribution of policy networks to the 
scale-up of antiretroviral therapy in Thailand. Health Policy Planning. 2008;23(5):328-338.

32. http://www.who.int/whosis/whostat/EN_WHS08_Full.pdf

33. Nishtar S. The mixed health systems syndrome: Bulletin of the World Health Organization. 2010;88(1):66-73.

34. Afzal U, Yusuf A. The state of health in Pakistan: An overview. 2013.

35. http://www.who.int/whosis/whostat/EN_WHSO9_Table7.pdf

36. Bank W. Delivering better health services to Pakistan's poor. 2010.

37. Bank W. World development indicators. 2012.

38. Ather F, Sherin A. Health system financing in Pakistan: reviewing resources and opportunities. Khyber Med University J. 2014;6(2):53-55.

39. Islam A. Bangladesh health system in transition. 2009.

40. Qarani WM, Kanji SI. Health system analysis: Pakistan and Afghanistan.

41. Shaikh B. Devolution in health sector: Challenges and opportunities for evidence based policies. 2013.

42. Rana SA. Preferences of doctors for working in rural islamabad capital territory, Pakistan: A qualitative study. J Ayub Med Coll Abbottabad. 2016;28(3):591-596.

43. Nishtar S. The Gateway Paper: Health Systems in Pakistan, a Way Forward. 2006.

44. Bano SK. Comparison and Analysis of Health Care Delivery Systems: Pakistan versus Bangladesh. J Hosp Med Manag. 2017;3(1):p:1.

45. Country cooperation strategy for WHO and Pakistan: 2011 2017. World Health Organization, Regional Office for the Eastern Mediterranean 2013.

46. Sabih F. Implementing the district health system in the framework of primary health care in Pakistan: Can the evolving reforms enhance the pace towards the Millennium Development Goals 2010.

47. http://www.dawnnewspakistan.com/mobile-phone-usersrange-132-million-in-pakistan/

48. Ghaffar A, Kazi BM, Salman M. Health care systems in transition III. An overview of the health care system in Pakistan. J Public Health. 2000;22(1):38-42.

49. Punjani NS, Shams S, Bhanji SM. Analysis of health care delivery systems: Pakistan versus United States. Int J Endorsing Health Sci Res. 2014;2(1):38-41.

50. Shah A. Fiscal federalism in Pakistan: Challenges and opportunities. 1996.

51. Nishtar S. Health reform in Pakistan: A call to action. Lancet. 2013;381(9885):2291-2297.

52. Ejaz I, Shaikh BT, Rizvi N. NGOs and government partnership for health systems strengthening: a qualitative study presenting viewpoints of government, NGOs and donors in Pakistan. BMC health Serv Res. 2011;11(1):p:122.

53. http://www.nspp.gov.pk/guideline/strategic-appraisal-of-18thamendment.pdf

54. Bossert TJ, Mitchell AD. Health sector decentralization and local decision-making: Decision space, institutional capacities and accountability in Pakistan. Soc Sci Med. 2011;72(1):39-48.

55. Social Policy and Development Center. Annual Review.

56. United Nation 2006 Department of Economic and Social Affairs. World Population Prospect. 2006.

57. World Bank. Partnering With NGOs to Strengthen Management: An External Evaluation of the Chief Minister's Initiative on Primary Health Care. 2006.

58. World Bank. Pakistan: Towards A Health Sector Strategy 1998. 